\title{
Contributions of the lead-bromine weighted bands to the occupied density of states of the hybrid tri-bromide perovskites
}
A. R. Kirmani, A. E. Mansour, M. I. Saidaminov, X. Cui, D. Shi, A. Alofi, Ya.

A. J. Yost, P. A. Dowben, E. Y. Tsymbal, A. Amassian, and K. Katsiev

Citation: Appl. Phys. Lett. 113, 022101 (2018); doi: 10.1063/1.5024527

View online: https://doi.org/10.1063/1.5024527

View Table of Contents: http://aip.scitation.org/toc/apl/113/2

Published by the American Institute of Physics

\section{Articles you may be interested in}

Electrical properties of extended defects in strain relaxed GeSn

Applied Physics Letters 113, 022102 (2018); 10.1063/1.5034573

Graphdiyne under pressure: A Raman study

Applied Physics Letters 113, 021901 (2018); 10.1063/1.5023619

Whispering gallery mode lasing in lead halide perovskite crystals grown in microcapillary

Applied Physics Letters 113, 011107 (2018); 10.1063/1.5037243

Enhanced stability of perovskite solar cells using hydrophobic organic fluoropolymer

Applied Physics Letters 113, 023902 (2018); 10.1063/1.5038917

Artificial electronic synapse characteristics of a $\mathrm{Ta} / \mathrm{Ta}_{2} \mathrm{O}_{5-x} / \mathrm{Al}_{2} \mathrm{O}_{3} / \mathrm{InGaZnO}_{4}$ memristor device on flexible stainless steel substrate

Applied Physics Letters 113, 013503 (2018); 10.1063/1.5027776

Impact of UV spot position on forward and reverse photocurrent symmetry in a gold-diamond-gold detector

Applied Physics Letters 113, 023501 (2018); 10.1063/1.5030139

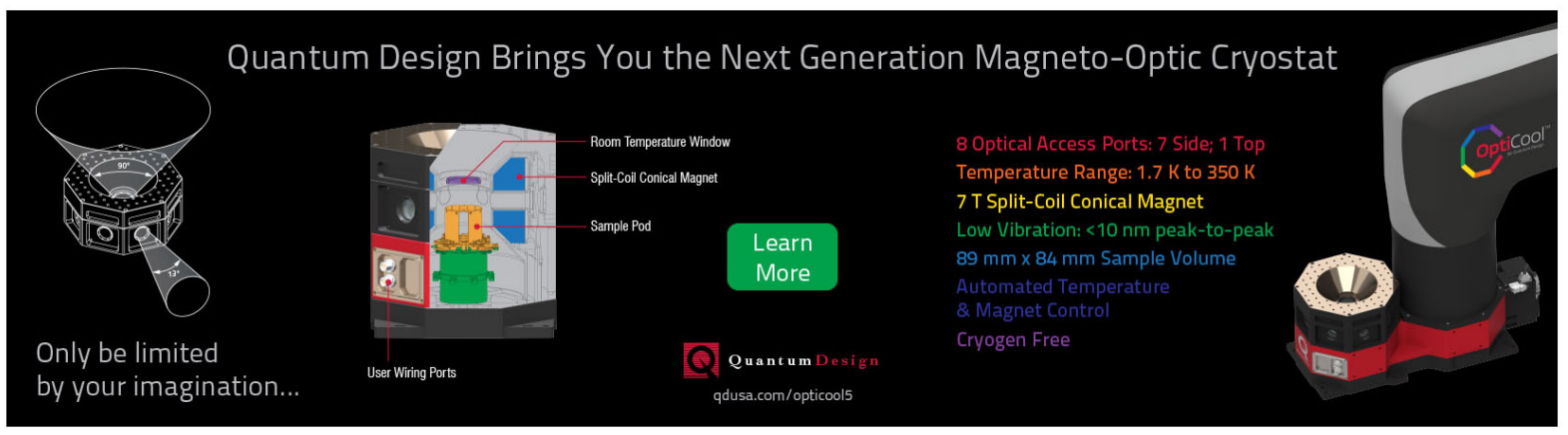




\title{
Contributions of the lead-bromine weighted bands to the occupied density of states of the hybrid tri-bromide perovskites
}

\author{
A. R. Kirmani, ${ }^{1}$ A. E. Mansour, ${ }^{1}$ M. I. Saidaminov, ${ }^{2}$ X. Cui, ${ }^{3}$ D. Shi, ${ }^{4}$ A. Alofi, ${ }^{2}$ \\ Ya. B. Losovyj, ${ }^{5}$ G. Gurung, ${ }^{6}$ T. R. Paudel, ${ }^{6}$ A. J. Yost, ${ }^{6}$ P. A. Dowben, ${ }^{6, a)}$ E. Y. Tsymbal, ${ }^{6}$ \\ A. Amassian, ${ }^{1, a)}$ and K. Katsiev ${ }^{7, a)}$ \\ ${ }^{1}$ KAUST Solar Center (KSC), Physical Sciences and Engineering Division (PSE), King Abdullah University \\ of Science and Technology (KAUST), Thuwal 23955-6900, Saudi Arabia \\ ${ }_{2}^{2}$ Physical Sciences and Engineering Division (PSE), King Abdullah University of Science and Technology \\ (KAUST), Thuwal 23955-6900, Saudi Arabia \\ ${ }^{3}$ Canadian Light Source, Saskatoon, Saskatchewan S7N 2V3, Canada \\ ${ }^{4}$ School of Optoelectronic Science and Engineering, University of Electronic Science and Technology, \\ Chengdu 610054, China \\ ${ }^{5}$ Department of Chemistry, Indiana University, Bloomington, Indiana 47405, USA \\ ${ }^{6}$ Department of Physics and Astronomy, Jorgensen Hall, 855 North 16th Street, University of \\ Nebraska-Lincoln, Lincoln, Nebraska 68588-0299, USA \\ ${ }^{7}$ SABIC Corporate Research and Innovation Center, King Abdullah University of Science and Technology \\ (KAUST), Thuwal 23955-6900, Saudi Arabia
}

(Received 1 February 2018; accepted 20 June 2018; published online 9 July 2018)

\begin{abstract}
The electronic structure of methylammonium lead bromide $\left(\mathrm{CH}_{3} \mathrm{NH}_{3} \mathrm{PbBr}_{3}\right)$ single crystals has been investigated through a combination of resonant photoemission and theoretical modeling. There are $\mathrm{Pb}$ spectral contributions throughout the valence band. Importantly, the electronic structure at the top of the valence band is found to be dominated by the hybridized $\mathrm{Pb}-\mathrm{Br}$ bands, not methylammonium bromide. The results line up with the partial density of states obtained from density functional theory and confirm that much of the valence band has some $\mathrm{Pb}$ spectral weight. Published by AIP Publishing. https://doi.org/10.1063/1.5024527
\end{abstract}

The past few years have been witness to a series of major breakthroughs in the field of hybrid organo-lead perovskites, specifically the methyl ammonium lead trihalide perovskites $\mathrm{MAPbX}_{3}\left(\mathrm{MA}=\mathrm{CH}_{3} \mathrm{NH}_{3}, \mathrm{X}=\mathrm{Cl}, \mathrm{Br}\right.$, I), as illustrated in Fig. 1. This intense attention is partly the result of better electronic properties exhibited by the single crystal materials, ranging from low defect state densities and long carrier diffusion lengths to high carrier mobilities coupled with the ease of solution processibility. ${ }^{1-4}$ Since the first demonstration of perovskite-based photovoltaics in 2009, highly efficient solar cells have been reported with certified power conversion efficiencies (PCE) breaching 22\%. Significant inroads are, as well, being made toward achieving long-term stability. ${ }^{6}$ Parallel efforts have been made at demonstrating light emission, ${ }^{7}$ photodetection ${ }^{8}$ and lasing applications of hybrid perovskites. ${ }^{9}$

There exist band structure calculations, ${ }^{10-27}$ valence band photoemission, ${ }^{12,27-37}$ and combined photoemission and inverse photoemission studies, ${ }^{26,28,37}$ aimed at elucidating the interfacial electronic band structure of the hybrid methyl ammonium-lead halide perovskites, $\mathrm{MAPbX}_{3}$. Despite these attempts, however, the nature of lead $(\mathrm{Pb})$ hybridization across the valence band remains poorly understood. This is important because the electronic structure at the top of the valence band plays a central role in photo-excitation and carrier transport, and an understanding of the region in the vicinity of the valence band maximum is important to the optoelectronic properties. Here, we have combined resonant

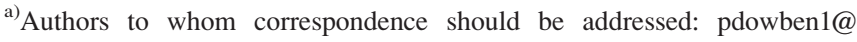
unl.edu, aram.amassian@kaust.edu.sa, and katsievk@sabic.com
}

photoemission spectroscopy and density functional theory (DFT) calculations to uncover the spectral contributions to valence band electronic structure of $\mathrm{MAPbBr}_{3}$ single crystals.

The crystals were synthesized using an antisolvent vapor-triggered crystallization approach reported elsewhere. ${ }^{2}$

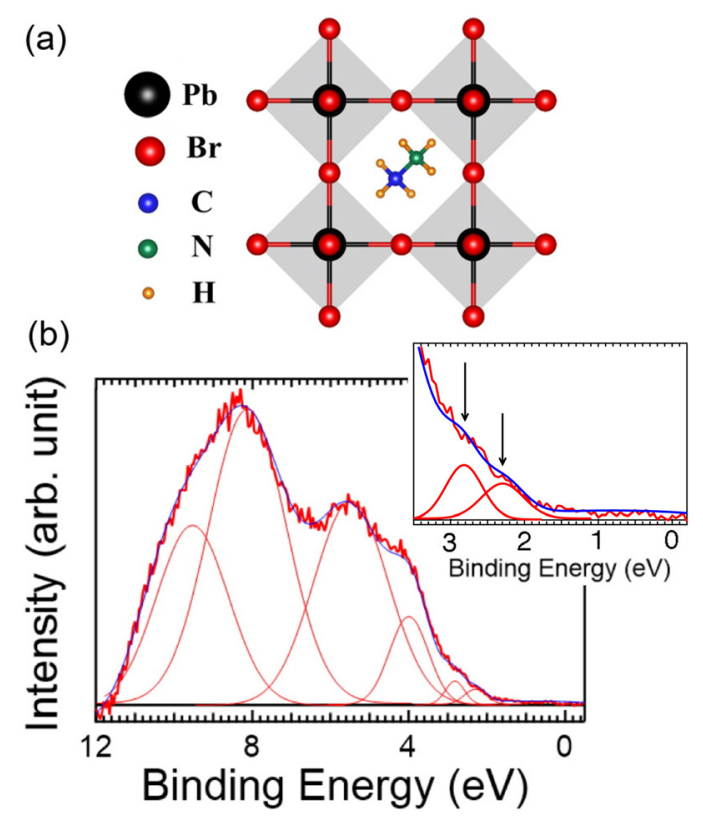

FIG. 1. (a) The cubic structure of $\mathrm{MAPbBr}_{3}$. (b) The valence band spectra of a $\mathrm{MAPbBr}_{3}$ single crystal determined by synchrotron-based photoemission spectroscopy. The valence band features (at binding energies around 2.3 and $2.8 \mathrm{eV})$, in the vicinity of the valence band maximum $\left(1.8 \mathrm{eV}^{26}\right)$, are shown in higher detail, in the inset. Taken at a photon energy of $35 \mathrm{eV}$ and binding energies, plotted as $\mathrm{E}_{\mathrm{F}}$-E. 
We have chosen the $\mathrm{MAPbBr}_{3}$ perovskite single crystals over the other types, since the stability of these crystals has been demonstrated in the ambient, ${ }^{38}$ while methylammonium lead triiodide $\left(\mathrm{MAPbI}_{3}\right)$ crystals are known to degrade in ambient conditions. ${ }^{39}$ The crystals were ca. $5 \mathrm{~mm} \times 3 \mathrm{~mm} \times 2 \mathrm{~mm}$ in dimensions.

To obtain detailed information on the states at the top of the valence band, we employed synchrotron-based photon energy-dependent photoemission spectroscopy. The studies were carried out at the photoemission end station of the plane grating mirror (PGM) beamline at Canadian Light Source, Inc., equipped with a Scienta SES100 hemispherical electron energy analyzer, with a total energy resolution of $50 \mathrm{meV}$. All the spectra were collected at normal emission and room temperature from $\mathrm{MAPbBr}_{3}(001)$ single crystals. Photon energies were tunable in the range of a few $\mathrm{eV}$ to a few-hundred eV. Spectra were calibrated using the Fermi edge of a sputter-cleaned $\mathrm{Cu}$ sample. The spot size of the photon beam was on the order of microns.

Figure 1(a) shows the typical crystal structure of the cubic $\mathrm{MaPbBr}_{3}$, along the (001) surface normal. Figure 1(b) shows the photoemission spectrum acquired from a $\mathrm{MAPbBr}_{3}(001)$ single crystal. Four main valance band features were observed at the binding energies $\left(\mathrm{E}_{\mathrm{F}}-\mathrm{E}\right)$ of roughly $4 \mathrm{eV}, 5.4 \mathrm{eV}, 8 \mathrm{eV}$, and $9.6 \mathrm{eV}$. Two weak intensity features in the valence band photoemission spectra are located at binding energies of 2.3 and $2.8 \mathrm{eV}$, as indicated by arrows, and the fittings to the experimental data, in the inset of Fig. 1(b). These states are close, in binding energy, to the top of the valence band which is seen to be at a binding energy of $1.8 \mathrm{eV}$, as measured at the Brillouin zone edge in a recent experimental band structure. ${ }^{26}$ Since the surface termination of $\mathrm{MAPbBr}_{3}(001)$ is $\mathrm{MABr},{ }^{25}$ these states observed in photoemission are consistent with bulk band states of the associated calculated band structure. ${ }^{25,26}$ Experimental verification of the bulk band structure character at the top of the valence band would require mapping the photon energy dependence of the valence band at the surface Brillouin zone edge high symmetry point $\overline{\mathrm{M}},{ }^{26}$ which was not done here. Such measurements would establish the presence or absence of dispersion in $\mathrm{k}_{\perp}$ (the presence or absence of conservation of 2-dimensionality of state), although it is clear that the top of the valence at $\bar{M}$ does not fall into a gap of the projected bulk band density of states. ${ }^{26}$ Such dispersion, in $\mathrm{k}_{\perp}$ at the surface Brillouin zone edge, but with wave vector along the surface normal, i.e., a photon energy dependent study, using angle resolved photoemission, was performed for methylammonium lead iodide $\left(\mathrm{CH}_{3} \mathrm{NH}_{3} \mathrm{PbI}_{3}\right)$ single crystals, ${ }^{32}$ establishing the bulk band character of the top of the valence band. For peak fitting, we used a Shirley background, with subsequent background subtraction. The valence band spectral features [Fig. 1(b)] were fitted with Gaussians as follows: a peak at a binding energy of $2.3 \mathrm{eV}\left(\mathrm{E}_{\mathrm{F}}-\mathrm{E}\right)$ with a full width at half maximum (FWHM) of $0.66 \mathrm{eV}$; a peak at $2.8 \mathrm{eV}$ with a FWHM $0.58 \mathrm{eV}$; a peak at $3.9 \mathrm{eV}$ with a FWHM $1.16 \mathrm{eV}$; a peak at $5.5 \mathrm{eV}$ with a FWHM $2.25 \mathrm{eV}$; a peak at $8.1 \mathrm{eV}$ with a FWHM $2.33 \mathrm{eV}$; and a peak at $10 \mathrm{eV}$ with a FWHM $2.16 \mathrm{eV}$.

To experimentally determine the lead spectral weight contributions to the valence band, especially near the top of the valence band, we employed an approach based on resonant photoemission enhancement of the partially-occupied valence $\mathrm{Pb} 6 \mathrm{p}$ levels. Resonant photoemission involves the resonance photoemission enhancement of the valence band by one of the shallow core levels of the system under study, ${ }^{40-43}$ and in this case the resonant process is

$$
5 d^{10} 6 s^{n} 6 p^{m}+h v \rightarrow 5 d^{9} 6 s^{n} 6 p^{m+1} \rightarrow 5 d^{10} 6 s^{n} 6 p^{m-1}+e^{-}
$$

or

$$
5 d^{10} 6 s^{n} 6 p^{m}+h v \rightarrow 5 d^{9} 6 s^{n} 6 p^{m+1} \rightarrow 5 d^{10} 6 s^{n-1} 6 p^{m}+e^{-},
$$

where an electron is excited to an unoccupied conduction band state, of $6 p$ character, which then collapses, causing resonant enhancement for occupied states containing either $\mathrm{Pb} 6 \mathrm{p}$ or $\mathrm{Pb} 6$ s spectral weight density. This leads to resonant enhancement of the direct photoemission process

$$
5 d^{10} 6 s^{n} 6 p^{m}+h v \rightarrow 5 d^{10} 6 s^{n} 6 p^{m-1}+e^{-}
$$

or

$$
5 d^{10} 6 s^{n} 6 p^{m}+h v \rightarrow 5 d^{10} 6 s^{n-1} 6 p^{m}+e^{-},
$$

respectively, and results in the same final state. ${ }^{43}$ The resonance enhancement in photoemission yields direct insights into elemental spectral contributions to a specific valence state and/or top-most valence band features of the material.

A 2D map of the resonant photoemission intensity for the valence band spectral features, in the binding energy region $0-5 \mathrm{eV}$, was acquired as a function of the photon energy $(h \nu=14-35 \mathrm{eV})$ and is shown in Fig. 2(a). The partial density of states (PDOS) intensity profile of the spectral features located around $c a .2 .25 \mathrm{eV}$ binding energy [indicated by vertical blue line in Fig. 2(a)] reveals the resonant enhancement at the photon energies of $22 \mathrm{eV}$ and $24.5 \mathrm{eV}$ [Fig. 2(b)]. These photon energies for the peak resonant photoemission occur at the $\mathrm{Pb} 5 \mathrm{~d}_{5 / 2}$ and $5 \mathrm{~d}_{3 / 2}$ shallow core level thresholds at binding energies of $19.8 \mathrm{eV}$ and $22.4 \mathrm{eV}$, respectively, as plotted in Fig. 3, plus the band gap of $2.3 \mathrm{eV},{ }^{11,26,44-48}$ as expected. Thus, we attribute the resonant enhancement to photoemission resonant transition from $\mathrm{Pb}$ $5 \mathrm{~d}$ to a partially unoccupied $\mathrm{Pb} 6 \mathrm{p}$ states, in the conduction band, and indicates a $\mathrm{Pb}$ contribution to most of the valence band, including the region near the top of the valence band. This type of resonant photoemission enhancement, of almost the entire valence band, has been seen for other perovskites, including the manganese perovskites. ${ }^{40-43}$ The very strong resonant enhancement seen here, in the photoemission as a function of photon energy, is also characteristic of a nonmetallic system, ${ }^{43}$ and indeed is expected as $\mathrm{MAPbBr}_{3}$ is a semiconductor, although metallic lead surface segregation can be a problem..$^{26,30,31,35}$ Several theoretical ${ }^{10-27}$ and experimental ${ }^{26,32}$ papers have the dispersion near the top of the valence band to be in the region of $1 \mathrm{eV}$ or less, and the dispersion of the heavy mass $\mathrm{Pb} 5 \mathrm{p}-\mathrm{Br} 4 \mathrm{p}$ bands (at a binding energy of $4 \mathrm{eV}$ ) to be in the region of several hundred meV or less. Thus, the results of Fig. 2(a) are not the result of bulk band dispersion, with changing photon energy. 

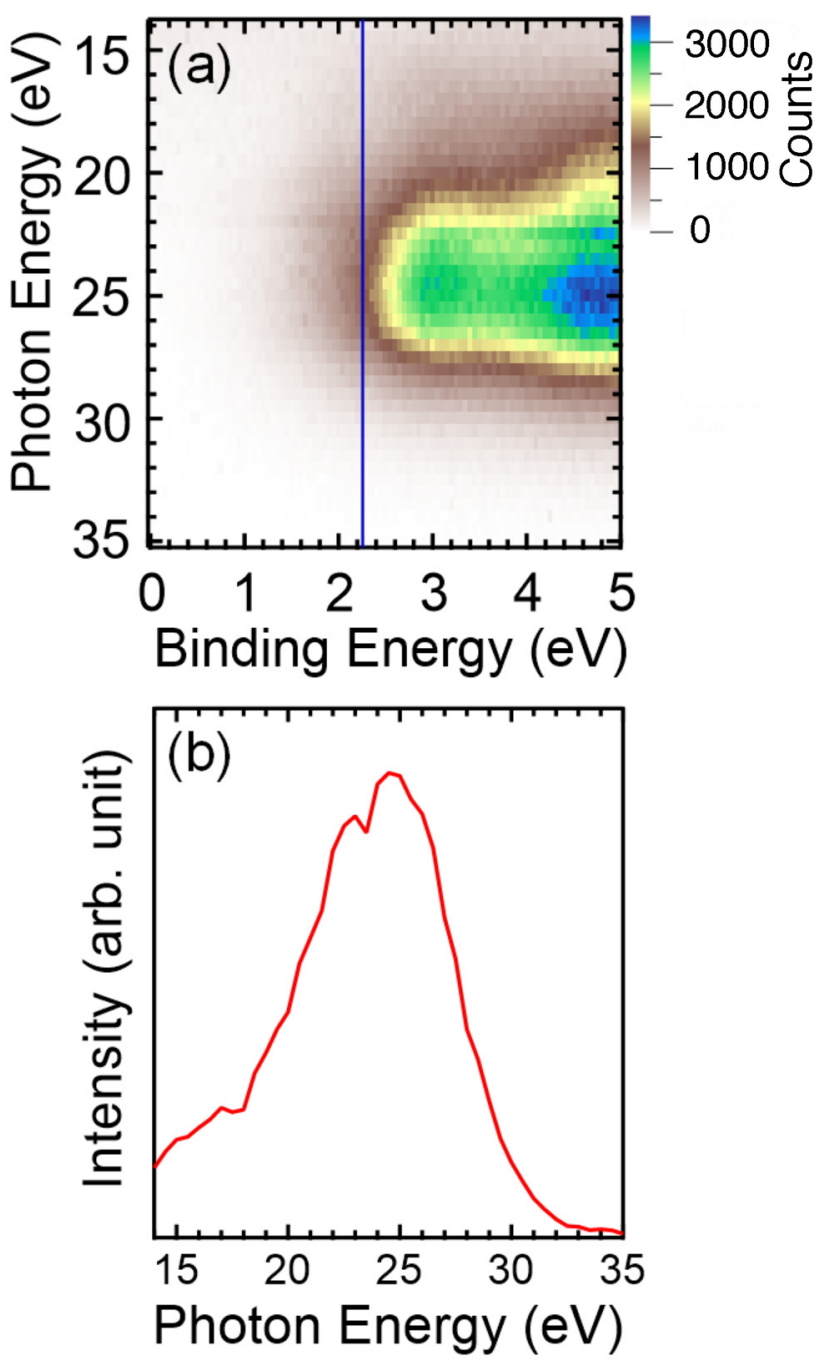

FIG. 2. (a) The results from resonant photoemission, constant initial state spectra, illustrated as a 2D map of the valence band photoemission intensities, as a function of the photon energy. (b) Resonant enhancement of the valence band in the region $2.3 \mathrm{eV}$ binding energy $\left(\mathrm{E}_{\mathrm{F}}-\mathrm{E}\right)$ as a function of photon energy, with the greatest enhancements occurring at photon energies corresponding to the binding energies of the $\mathrm{Pb} 5 \mathrm{~d}$ shallow core levels.

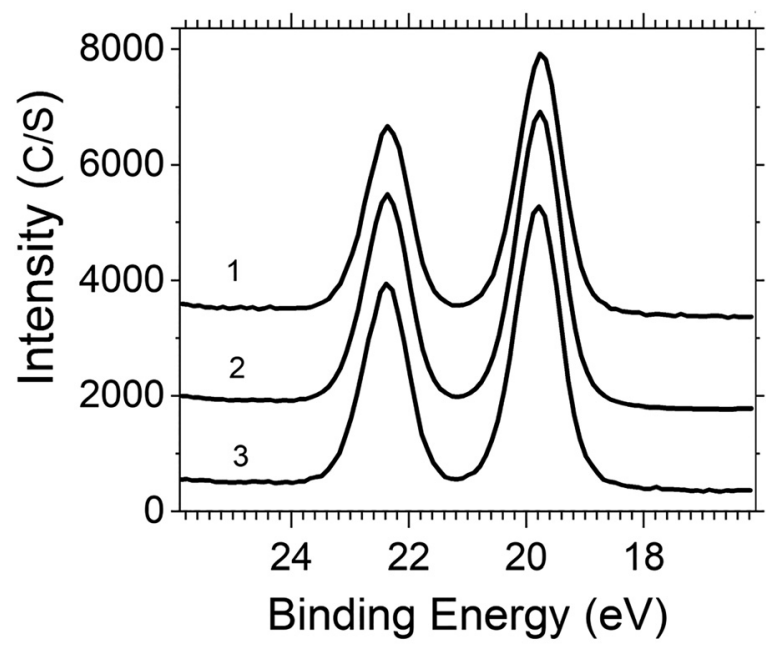

FIG. 3. The $\mathrm{Pb} 5 \mathrm{~d}$ core levels from three different $\mathrm{MAPbBr}_{3}$ single crystals, as established by X-ray photoemission using a PHI Versa Probe II instrument equipped with monochromatic Al K(alpha) source. Spectra are offset for clarity.
To further confirm the spectral contributions to the states at the top of the valence band, we calculated the electronic band structure of $\mathrm{MAPbBr}_{3}$ using density functional theory (DFT). We employed the projected augmented wave (PAW) method for the electron-ion potential, ${ }^{49}$ the generalized gradient approximation (GGA) for exchange-correlation potential, ${ }^{50}$ and relativistic corrections including spin-orbit coupling as implemented in Vienna ab-initio simulation package (VASP). ${ }^{51,52}$ The calculations were carried out using a $640 \mathrm{eV}$ kinetic energy cutoff and $12 \times 12 \times 12 \mathrm{k}$ point mesh. We fully relaxed the ionic coordinates with the force convergence limit of $0.001 \mathrm{eV} /$ atom. The theoretical lattice constant of $5.96 \AA$ was used, and we maintained cubic lattice symmetry in the calculations. In GGA, it is well known that band gap is underestimated, and as a result we have shifted the conduction band by $1.37 \mathrm{eV}$ to better match the experimental band gap of $2.33 \mathrm{eV} .^{53}$

The calculated partial density of states (PDOS) of a cubic $\mathrm{MAPbBr}_{3}$ crystal [Fig. 1(a)] has been plotted in Fig. 4. We have used the tetrahedral method to calculate the partial density of states; therefore, Fig. 4 has no smearing included. The majority of the valence band is dominated by $\mathrm{Br}-\mathrm{p}$ orbitals while the conduction band is dominated by $\mathrm{Pb}-\mathrm{p}$ orbitals. ${ }^{26}$ The top of the valence band, however, has almost equivalent contributions from $\mathrm{Pb}$-s and $\mathrm{Br}$-p orbitals, ${ }^{26,27}$ as applicable to a single $\mathrm{Pb}-\mathrm{Br}$ layer. The MA-Br layer should dominate the photoemission as this would be the surface

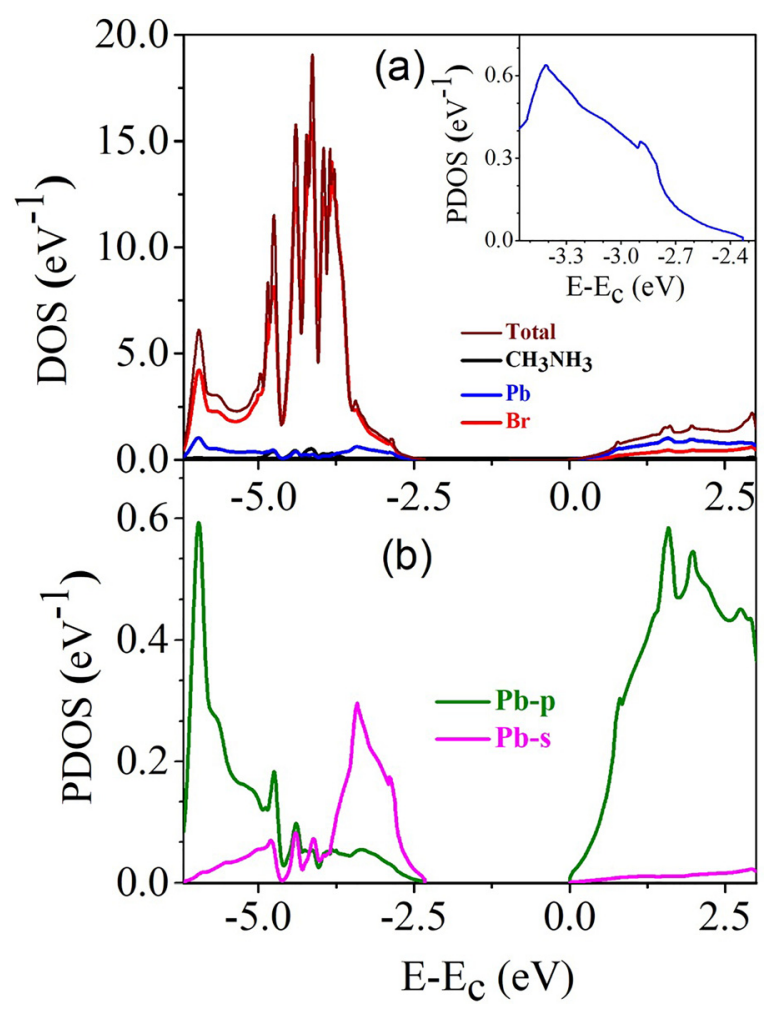

FIG. 4. Partial density of states (PDOS) of $\mathrm{MAPbBr}_{3}$ showing (a) the contributions of $\mathrm{Pb}$ and $\mathrm{Br}$ atoms and the $\mathrm{CH}_{3} \mathrm{NH}_{3}$ molecule, in the presence of spin-orbit coupling, as well as the total density of states corrected for a full unit cell and (b) the relative contributions of Pb-p (green) and $\mathrm{Pb}-\mathrm{s}$ (violet). The binding energy $(E)$ is defined with respect to the energy of the conduction band minima $\left(\mathrm{E}_{\mathrm{c}}\right)$. Inset shows the $\mathrm{Pb}$ weight at the valence band maximum. 
terminal layer, ${ }^{25,26}$ as noted earlier. Lindblad and coworkers ${ }^{36}$ have the top of the valence band dominated almost exclusively by $\mathrm{Br}$ spectral weight, which results from the fairly heavy overall $\mathrm{Br}$ spectral weight contributions, but does not correct for the surface sensitivity of photoemission. The occupied states corresponding to the $\mathrm{CH}_{3} \mathrm{NH}_{3}$ molecule lie far below the valence band maximum. Due to the large contribution of $\mathrm{Pb}-\mathrm{p}$ orbitals in the conduction band, spinorbit coupling mainly affects the conduction band. There are two states that appear in the calculated PDOS, ca. 0.5 and $1 \mathrm{eV}$ below the valence band maximum, or $2.8 \mathrm{eV}$ and $3.4 \mathrm{eV}$ below the conduction band edge. If the valence band maximum is placed at a binding energy of $1.8 \mathrm{eV}$, as indicated by prior work on $\mathrm{MAPbBr}_{3},{ }^{26}$ then in experiment, these features near the top of the valence band in the PDOS (inset of Fig. 4) would appear at $2.3 \mathrm{eV}$ and $2.8 \mathrm{eV}$. This is very close to what is observed in photoemission $(2.3 \mathrm{eV}$ and $2.8 \mathrm{eV})$, as seen in Fig. 2.

In summary, we have explored the electronic structure of $\mathrm{MAPbBr}_{3}$ single crystals in the vicinity of the valence band maximum, using a combination of resonant photoemission spectroscopy and density functional theory. Our studies suggest that the top of the valence band of these hybrid perovskites has spectral contributions from both $\mathrm{Pb}$ and $\mathrm{Br}$ and is dominated by $\mathrm{Pb}-\mathrm{Br}$ hybridized bands. Based on other studies, ${ }^{26,32}$ these bands are not surface state bands, rather contain strong bulk character.

The single crystals used in this study were synthesized in the Functional Nanomaterials Lab (FuNL), KAUST, headed by Professor Osman M. Bakr, whose helpful comments on the results and conclusions of this study are acknowledged. The support of King Abdullah University of Science and Technology (KAUST) and Saudi Arabia Basic Industries Corporation (SABIC) is acknowledged. The work at the University of Nebraska was supported by the National Science Foundation through the Nebraska MRSEC (Grant No. DMR-1420645), the Nebraska Center for Energy Science and Research.

${ }^{1}$ G. Xing, N. Mathews, S. Sun, S. S. Lim, Y. M. Lam, M. Grätzel, S. Mhaisalkar, and T. C. Sum, Science 342, 344 (2013).

${ }^{2}$ D. Shi, V. Adinolfi, R. Comin, M. Yuan, E. Alarousu, A. Buin, Y. Chen, S. Hoogland, A. Rothenberger, K. Katsiev, Y. Losovyj, X. Zhang, P. A. Dowben, O. F. Mohammed, E. H. Sargent, and O. M. Bakr, Science 347, 519 (2015).

${ }^{3}$ M. I. Saidaminov, A. L. Abdelhady, B. Murali, E. Alarousu, V. M. Burlakov, W. Peng, I. Dursun, L. Wang, Y. He, G. Maculan, A. Goriely, T. Wu, O. F. Mohammed, and O. M. Bakr, Nat. Commun. 6, 7586 (2015).

${ }^{4}$ Q. Dong, Y. Fang, Y. Shao, P. Mulligan, J. Qiu, L. Cao, and J. Huang, Science 347, 967-970 (2015).

${ }^{5}$ M. A. Green, K. Emery, Y. Hishikawa, W. Warta, and E. D. Dunlop, Prog. Photovoltaics Res. Appl. 23, 1-9 (2015).

${ }^{6}$ G. Grancini, C. Roldán-Carmona, I. Zimmermann, E. Mosconi, X. Lee, D. Martineau, S. Narbey, F. Oswald, F. De Angelis, M. Graetzel, and M. K. Nazeeruddin, Nat. Commun. 8, 15684 (2017).

${ }^{7}$ H. Cho, S.-H. Jeong, M.-H. Park, Y.-H. Kim, C. Wolf, C.-L. Lee, J. H. Heo, A. Sadhanala, N. Myoung, S. Yoo, S. H. Im, R. H. Friend, and T.-W. Lee, Science 350, 1222 (2015).

${ }^{8}$ M. I. Saidaminov, V. Adinolfi, R. Comin, A. L. Abdelhady, W. Peng, I. Dursun, M. Yuan, S. Hoogland, E. H. Sargent, and O. M. Bakr, Nat. Commun. 6, 8724 (2015).

${ }^{9}$ H. Zhu, Y. Fu, F. Meng, X. Wu, Z. Gong, Q. Ding, M. V. Gustafsson, M. T. Trinh, S. Jin, and X. Y. Zhu, Nat. Mater. 14, 636 (2015).
${ }^{10}$ Q. Chen, N. De Marco, Y. Yang, T.-B. Song, C.-C. Chen, H. Zhao, Z. Hong, H. Zhou, and Y. Yang, Nanotoday 10, 355-396 (2015).

${ }^{11}$ T. Shi, W.-J. Yin, F. Hong, K. Zhu, and Y. Yan, Appl. Phys. Lett. 106, 103902 (2015).

${ }^{12}$ H.-J. Feng, T. R. Paudel, E. Y. Tsymbal, and X. C. Zeng, J. Am. Chem. Soc. 137, 8227 (2015).

${ }^{13}$ J.-S. Park, S. Choi, Y. Yan, Y. Yang, J. M. Luther, S.-H. Wei, P. Parilla, and K. Zhu, J. Phys. Chem. Lett. 6, 4304 (2015).

${ }^{14}$ T. Umebayashi, K. Asai, T. Kondo, and A. Nakao, Phys. Rev. B 67, 155405 (2003).

${ }^{15}$ W. Geng, C.-T. Tong, Z.-K. Tang, C. Yam, Y.-N. Zhang, W.-M. Lau, and L.-M. Liu, J. Materiomics 1, 213-220 (2015).

${ }^{16}$ E. Mosconi, A. Amat, M. K. Nazeeruddin, M. Grätzel, and F. De Angelis, J. Phys. Chem. C 117, 13902 (2013).

${ }^{17}$ T. Baikie, Y. Fang, J. M. Kadro, M. Schreyer, F. Wei, S. G. Mhaisalkar, M. Graetzel, and T. J. White, J. Mater. Chem. A 1, 5628-5641 (2013).

${ }^{18}$ J. Even, L. Pedesseau, C. Katan, M. Kepenekian, J.-S. Lauret, D. Sapori, and E. Deleporte, J. Phys. Chem. C 119, 10161-10177 (2015).

${ }^{19}$ J. Even, L. Pedesseau, and C. Katan, J. Phys. Chem. C 118, 11566-11572 (2014).

${ }^{20}$ J. Even, L. Pedesseau, J.-M. Jancu, and C. Katan, J. Phys. Chem. Lett. 4, 2999-3005 (2013).

${ }^{21}$ M. Kepenekian, R. Robles, C. Katan, D. Sapori, L. Pedesseau, and J. Even, ACS Nano 9, 11557-11567 (2015).

${ }^{22}$ G. Giorgi, J.-I. Fujisawa, H. Segawa, and K. Yamashita, J. Phys. Chem. Lett. 4, 4213-4216 (2013).

${ }^{23}$ P. Umari, E. Mosconi, and F. De Angelis, Sci. Rep. 4, 4467 (2014).

${ }^{24}$ F. Brivio, K. T. Butler, A. Walsh, and M. van Schilfgaarde, Phys. Rev. B 89, 155204 (2014).

${ }^{25}$ X. Huang, T. R. Paudel, P. A. Dowben, S. Dong, and E. Y. Tsymbal, Phys. Rev. B 94, 195309 (2016).

${ }^{26}$ T. Komesu, X. Huang, T. R. Paudel, Y. B. Losovyj, X. Zhang, E. F. Schwier, Y. Kojima, M. Zheng, H. Iwasawa, K. Shimada, M. I. Saidaminov, D. Shi, A. L. Abdelhady, O. M. Bakr, S. Dong, E. Y. Tsymbal, and P. A. Dowben, J. Phys. Chem. C 120, 21710 (2016).

${ }^{27}$ J. Qian, B. Xu, and W. Tian, Org. Electron. 37, 61-73 (2016).

${ }^{28}$ C. Wang, X. Liu, C. Wang, Z. Xiao, C. Bi, Y. Shao, J. Huang, and Y. Gao, J. Vac. Sci. Technol., B 33, 032401 (2015).

${ }^{29}$ M. Kollár, L. Ćirić, J. H. Dil, A. Weber, S. Muff, H. M. Ronnow, B. Náfrádi, B. P. Monnier, J. S. Luterbacher, L. Forró, and E. Horváth, Sci. Rep. 7, 695 (2017).

${ }^{30}$ G. Sadoughi, D. E. Starr, E. Handick, S. D. Stranks, M. Gorgoi, R. G. Wilks, M. Bär, and H. J. Snaith, ACS Appl. Mater. Interfaces 7, 13440-13444 (2015).

${ }^{31}$ B. Conings, L. Baeten, C. De Dobbelaere, J. D'Haen, J. Manca, and H.-G. Boyen, Adv. Mater. 26, 2041-2046 (2014).

${ }^{32}$ M.-I. Lee, A. Barragán, M. N. Nair, V. L. R. Jacques, D. Le Bolloc'h, P. Fertey, K. Jemli, F. Lédée, G. Trippé-Allard, E. Deleporte, A. TalebIbrahimi, and A. Tejeda, J. Phys. D: Appl. Phys. 50, 26LT02 (2017).

${ }^{33}$ R. Lindblad, D. Bi, B.-W. Park, J. Oscarsson, M. Gorgoi, H. Siegbahn, M. Odelius, E. M. J. Johansson, and H. Rensmo, J. Phys. Chem. Lett. 5, 648-653 (2014).

${ }^{34}$ D. Niesner, M. Wilhelm, I. Levchuk, A. Osvet, S. Shrestha, M. Batentschuk, C. Brabec, and T. Fauster, Phys. Rev. Lett. 117, 126401 (2016).

${ }^{35}$ F.-S. Zu, P. Amsalem, I. Salzmann, R.-B. Wang, M. Ralaiarisoa, S. Kowarik, S. Duhm, and N. Koch, Adv. Opt. Mater. 5, 1700139 (2017).

${ }^{36}$ R. Lindblad, N. K. Jena, B. Philippe, J. Oscarsson, D. Bi, A. Lindblad, S. Mandal, B. Pal, D. D. Sarma, O. Karis, H. Siegbahn, E. M. J. Johansson, M. Odelius, and H. Rensmo, J. Phys. Chem. C 119, 1818-1825 (2015).

${ }^{37}$ J. Endres, D. A. Egger, M. Kulbak, R. A. Kerner, L. Zhao, S. H. Silver, G. Hodes, B. P. Rand, D. Cahen, L. Kronik, and A. Kahn, J. Phys. Chem. Lett. 7, 2722-2729 (2016).

${ }^{38}$ H.-H. Fang, S. Adjokatse, H. Wei, J. Yang, G. R. Blake, J. Huang, J. Even, and M. A. Loi, Sci. Adv. 2, e1600534 (2016).

${ }^{39}$ J. F. Galisteo-López, M. Anaya, M. E. Calvo, and H. Míguez, J. Phys. Chem. Lett. 6, 2200 (2015).

${ }^{40}$ D. N. McIlroy, J. Zhang, S.-H. Liou, and P. A. Dowben, Phys. Lett. A 207, 367-373 (1995).

${ }^{41}$ J. Zhang, D. N. McIlroy, P. A. Dowben, S.-H. Liou, S. F. Sabiryanov, and S. S. Jaswal, Solid State Commun. 97, 39-44 (1996).

${ }^{42}$ D. N. McIlroy, C. Waldfried, J. Zhang, J.-W. Choi, F. Foong, S.-H. Liou, and P. A. Dowben, Phys. Rev. B 54, 17438-17451 (1996).

${ }^{43}$ P. A. Dowben, Surf. Sci. Rep. 40, 151 (2000).

${ }^{44}$ R. Sheng, A. Ho-Baillie, S. Huang, S. Chen, X. Wen, X. Hao, and M. A. Green, J. Phys. Chem. C 119, 3545-3549 (2015). 
${ }^{45}$ Y. Yang, M. Yang, Z. Li, R. Crisp, K. Zhu, and M. C. Beard, J. Phys. Chem. Lett. 6, 4688-4692 (2015).

${ }^{46}$ D. Priante, I. Dursun, M. S. Alias, D. Shi, V. A. Melnikov, T. K. Ng, O. F. Mohammed, O. M. Bakr, and B. S. Ooi, Appl. Phys. Lett. 106, 081902 (2015).

${ }^{47}$ N. Kitazawa, Y. Watanabe, and Y. Nakamura, J. Mater. Sci. 37, 3585 (2002).
${ }^{48}$ K. Tanaka, T. Takahashi, T. Ban, T. Kondo, K. Uchida, and N. Miura, Solid State Commun. 127, 619-623 (2003).

${ }^{49}$ P. E. Blöchl, Phys. Rev. B 50, 17953 (1994).

${ }^{50}$ J. P. Perdew, K. Burke, and M. Ernzerhof, Phys. Rev. Lett. 77, 3865 (1996).

${ }^{51}$ G. Kresse and J. Furthmüller, Phys. Rev. B 54, 11169 (1996).

${ }^{52}$ G. Kresse and D. Joubert, Phys. Rev. B 59, 1758 (1999).

${ }^{53}$ G. C. Papavassiliou and I. B. Koutselas, Synth. Met. 71, 1713 (1995). 